\title{
ФОРМИРОВАНИЕ ЦИФРОВЫХ НАВЫКОВ НА ПЕРВОМ КУРСЕ ЭКОНОМИЧЕСКОГО БАКАЛАВРИАТА
}

\section{FORMATION OF DIGITAL SKILLS ON THE FIRST COURSE ECONOMIC BACHELOR}

L. Konnova

I. Stepanyan

Summary: The article discusses the possibilities of forming digital skills in the first year of an economic university. Based on the competencies of the discipline «Data Analysis», the basic skills necessary for the initial analysis of data, visualization, and the use of Internet sources of information are highlighted. Describes the methods of forming appropriate skills in the framework of computer practice classes using Excel and $R$.

Keywords: digital literacy, digital skills, computer workshop, data analysis.

\author{
Коннова Лариса Петровна \\ к.п.н., дочент, Финансовый университет при \\ Правительстве Российской Федерации; \\ Степанян Ирина Кимовна \\ к.п.н., доцент, Финансовый университет при \\ Правительстве Российской Федерации \\ fpk0701@mail.ru
}

Аннотация: В статье рассматриваются возможности формирования цифровых навыков на первом курсе экономического вуза. На основе компетенций дисциплины «Анализ данных» выделяются базовые умения, необходимые для первичного анализа данных, визуализации, использования интернет-источников информации. Описываются методы формирования соответствующих навыков в рамках занятий по компьютерному практикум с использованием Excel $и$ R.

Ключевые слова: цифровая грамотность, цифровые навыки, компьютерный практикум, анализ данных.

стемами блокчейн, искусственным интеллектом, криптовалютами;

- разработка электронных средств обучения, позволяющих выстраивать индивидуальные траектории обучения;

- использование в образовательной среде современных цифровых технологий: прокторинга, мгновенной проверки, геймификации;

- формирование цифровых навыков и личностных качеств у студентов для успешного взаимодействия и работы в цифровой среде.

Все эти вопросы активно обсуждаются в научном педагогическом сообществе. Проблемам и перспективам подготовки кадров для цифровой экономики посвящен целый ряд докладов, сделанных в рамках Всероссийской научно-практической конференции «Вызовы цифровой экономики: итоги и новые тренды» [2], XXIII Международной научно-практической конференции, посвященной 100-летию финансового университета при правительстве российской федерации «Экономические, финансовые и управленческие аспекты внедрения цифровых технологий» [3], XVI Международной научнопрактической конференции студентов, магистрантов и аспирантов «Цифровые технологии в социально-экономическом развитии России: взгляд молодых» [4] .

В основном, пока идет процесс осмысления задач, поставленных правительством перед вузами.

Нет сомнений, что входящие в нашу жизнь, сквозные технологии цифровой экономики, обозначен- 
ные правительством (https://digital.gov.ru/ru/activity/ directions/878/): большие данные; новые производственные технологии; промышленный интернет; искусственный интеллект; технологии беспроводной связи; компоненты робототехники и сенсорика; квантовые технологии; системы распределенного реестра; технологии виртуальной и дополненной реальностей должны стать основой специальных учебных дисциплин. А это значит, должны быть разработаны соответствующие программы, учебные и методические материалы, сформированы банки данных различных профессиональных компетенций в рамках цифровой экономики.

Помимо введения новых в традиционном смысле «учебных» дисциплин, появляются различные инновационные образования, активно использующие современные технологии. В статье [2, с. 190-194)] речь идет о создании «инновационных систем (хабов)» - соединении цифровых технологий, передовых бизнес-идей и направлений. Объектами инновационной деятельности могут быть научно-исследовательские, опытно-конструкторские и инновационно-предпринимательские проекты. Похожий проект существует и в Финансовом университете - Чапай Хаб, где предлагаются различные программы с уникальными возможностями достижения долгосрочного успеха для студентов, стартапов, инвесторов и компаний [http://chapayhub.fa.ru/].

Специальный учебный модуль, ставящий целью «создать микроклимат для рождения инновационных подходов к обучению, сформировать экосистему для развития высокотехнологичного предпринимательства» описывают в своей работе [5] педагоги Саратовского физикотехнического института. Авторы обращают внимание на противоречие в подготовке специалистов технических и экономических профилей, в результате которого и тем, и другим не хватает компетенций для ведения наукоемкого бизнеса. Так, студентам экономических вузов не дают предметных знаний в области высоких технологий и процесса создания инноваций. В свою очередь, программы технических факультетов, в основном, не включают изучение основ предпринимательства и коммерциализации результатов научного труда. Разработанный дополнительный образовательный модуль позволяет сформировать компетенций для инновационной деятельности и самостоятельной проектной работе.

Подготовка кадров для цифровой экономики не может происходить без серьезного преобразования самих образовательных ресурсов. Для их подготовки должны быть использованы современные средства. Так, уже прочно вошедшие в образовательную среду онлайнкурсы должны разрабатываться в более высокотехнологичных сферах. Обязательными здесь должны стать элементы машинного обучения, дополненная и виртуальная реальность, системы прокторинга.
Одним из приоритетов программы «Цифровая экономика РФ» является цифровая грамотность населения и, в первую очередь конечно, современных специалистов. Решение этой задачи должно решаться комплексно, в процессе всего обучения в университете. По определению, представленному в работе [2, с. 447-452], цифровая грамотность - это способность создавать и использовать контент с помощью цифровых технологий, включая навыки компьютерного программирования, поиск и обмен информацией, коммуникацию с другими людьми.

Вопросам развития цифровой грамотности студентов посвящена статья [6] Авторы приводят результаты анкетирования студентов, в том числе первого курса, по имеющимся у них навыкам использования различных интернет-ресурсов. Показывается, что у бакалавров достаточно хорошо развиты умения быстрого поиска информации развлекательного характера и ее архивирования, онлайн-коммуникации, но не хватает навыков, требующих развитых аналитических и стратегических умений работы с найденной информацией. То есть без специального обучения у студентов цифровая компетентность формируется недостаточно. В работе делается вывод, что цифровая грамотность - комплекс знаний, умений и навыков, которые подразделяются на операционные, инструментальные, аналитические и стратегические. Задача преподавателей задействовать в работе все характеристики цифровой грамотности.

Формирование цифровых компетенций, так называемых Digital Skills, становится необходимым условием подготовки современного специалиста экономического и финансового профиля.

О важности развития цифровой грамотности для студентов экономических направлений речь идет в статье [7]. Автор считает, что обучение навыкам работы с современными компьютерными технологиями нужно начинать сразу на первом курсе, включая традиционные базовые дисциплины. В работе предлагается использовать редактор Excel для решения задач в процессе изучения микроэкономики и экономической теории.

В Финансовом университете активно происходят изменения, касающиеся всех, описанных выше, направлений внедрения цифровых технологий в учебный процесс. Департаментом анализа данных, принятия решений и финансовых технологий с 2017 года уже на первом курсе введена новая дисциплина «Компьютерный практикум». Ее цель - формирование практических навыков по использованию компьютерных технологий, используемых в экономике и финансах. Содержательно курс дополняет дисциплину «Математика» и позволяет более детально знакомиться с вычислительными методами, реализовывать различные алгоритмы, визуализировать зависимости. Введение новой дисциплины реа- 
лизует стратегическую линию университета на раннюю профилизацию образования [8].

Практически этот курс позволяет начать системную работу по формированию цифровой грамотности студентов в том объеме, в котором это необходимо современному экономисту.

Формирование цифровых навыков начинается для студентов первого курса на Компьютерном практикуме и продолжается далее при изучении дисциплины Анализ данных на втором курсе. Практические занятия по этой дисциплине проходят в компьютерных классах, что позволяет выстроить сквозную линию формирования цифровых навыков уже на первых годах обучения в университете. Содержательная и технологическая связь, выстроенная на основе преемственности, делает возможным заложить прочную основу для развития навыков использования IT-инструментов в предметной области и формирования цифровой грамотности студентов.

Рассмотрим более подробно возможности организации такой обучающей линии.

Согласно рабочей программе дисциплины Компьютерный практикум [9] набор соответствующих компетенций для студентов первого курса Финансового университета, обучающихся по направлению подготовки «Экономика», следующий:

- ПКН-3 - способность применять математические методы для решения стандартных профессиональных финансово-экономических задач, интерпретировать полученные математические результаты;

- ИК-2 - способность работать на компьютере с использованием современного общего и профессионального прикладного программного обеспечения;

- ИК-5 - способность применять методики расчетов и основные методы исследований.

С другой стороны, согласно Рабочей программе дисциплины Анализ данных по направлению подготовки «Экономика» [10] студенты второго курса бакалавриата должны овладеть следующими компетенциями:

- ПкН-1 - владение основными научными понятиями и категориальным аппаратом современной экономики и их применение при решении прикладных задач;

- ПКН-3 - способность осуществлять сбор, обработку и статистический анализ данных, применять математические методы для решения стандартных профессиональных финансово-экономических задач, интерпретировать полученные результаты;

- ПКН-4 - способность оценивать показатели дея-

тельности экономических субъектов.

Соответствие индикаторов достижения планируемых результатов для определения результатов студентов в изучении обеих дисциплин и овладения компетенциями, представлены в таблице 1.

Таблица 1

Результаты обучения, соотнесенные с компетенциями для дисциплин Компьютерный практикум (КП) и Анализ данных(АД)*
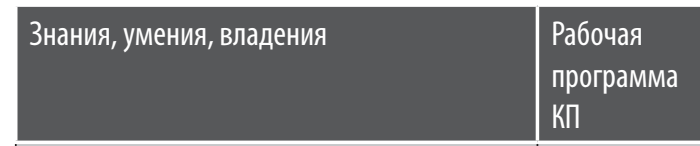

Рабочая программа

Знать вычислительные методики основных математических задач, используемых в экономике и финансах.

Уметь использовать компьютерные технологии при реализации математических методов и моделей для описания и анализа прикладных задач.

\begin{tabular}{ll|l|l|}
\hline $\begin{array}{l}\text { Владеть навыками вычислительной ра- } \\
\text { боты в ЕхсеІ и R. }\end{array}$ & ПКН-3 & ПКН-3 \\
\hline $\begin{array}{l}\text { Знать основные средства визуализации } \\
\text { количественных данных, используемых в } \\
\text { управлении. }\end{array}$ & ИК-2 & $\begin{array}{l}\text { ПКН-1, } \\
\text { ПКН-4 }\end{array}$ & ПКН-1, \\
\hline $\begin{array}{l}\text { Уметь использовать компьютерные тех- } \\
\text { нологии представления данных и графи- } \\
\text { ческой визуализации результатов приме- } \\
\text { нения математических методов и моделей } \\
\text { для описания и анализа прикладных задач. }\end{array}$ & ИК-2 & ПКН- \\
\hline $\begin{array}{l}\text { Владеть навыками работы в ЕхсеІ и R в } \\
\text { части визуализации количественных дан- } \\
\text { ных. }\end{array}$ & ИК-2 & ПКН-1 \\
\hline $\begin{array}{l}\text { Знать вычислительные методики рас- } \\
\text { четов основных математических задач, ис- } \\
\text { пользуемых в экономике и финансах; }\end{array}$ & ИК-5 & ПКН-4 \\
\hline $\begin{array}{l}\text { Уметь использовать компьютерные тех- } \\
\text { нологии при реализации вычислительных } \\
\text { методик математических методов и моде- } \\
\text { лей описания и анализа задач экономики и } \\
\text { финансов. }\end{array}$ & ИК-5 & ПКН-4 \\
\hline $\begin{array}{l}\text { Владеть навыками вычислительной ра- } \\
\text { боты в ЕхсеІ и R. }\end{array}$ & ИК-5 & ПКН-4 \\
\hline
\end{tabular}

*B таблице перечислены все знания, умения и владения для Компьютерного практикума. Некоторые индикаторы из рабочей программы дисциплины Анализ данных, не опорные для нашего исследования, не представлены, чтобы упростить схему контент-анализа.

Как видно из таблицы 1, компетенции для обеих дисциплин либо совпадают, как компетенции с шифром ПКН-3, либо опираются на совпадающие знания, умения 
и владения.

Сравнительный анализ компетенций убеждает, что преподавание Компьютерного практикума на первом курсе и Анализа данных на втором курсе должно осуществляться в духе преемственности и междисциплинарного взаимодействия.

Накопленный опыт преподавания дисциплины Компьютерный практикум позволяет привести примеры заданий, демонстрирующих методы начального формирования цифровых навыков.

Конкретизируя положения программы, выделим, на наш взгляд, базовые умения и навыки, формирующие фундамент цифровых навыков.

1. Скачивать данные из различных электронных ресурсов, форматировать согласно требованиям и иелям.

Наибольший интерес для студентов представляют реальные данные. Поэтому уже на начальном этапе обучения формирования и форматирования таблиц в Excel можно использовать данные Росстата, биржевую информацию, отчеты различных статистических агентств и базы данных. Изучая различные типы данных, нужно добиваться чтобы информация после скачивания была представлена в требуемом виде. Важную роль здесь играют различные формы представления чисел, даты и времени. Полезно использовать иностранные источники данных, обращая при этом внимание на отличия формата данных в разных странах и регионах. Такая же работа по изучению различных типов данных проводится и при начальном знакомстве C R.

2. Фильтровать, сортировать данные, выделять элементы и группы элементов.

У студентов должны быть сформированы устойчивые навыки по упорядочиванию элементов массива, различных видов сортировки с использованием фильтров, обращению к отдельным элементам массива или вектора, выделению из общего массива данных определенных матриц и столбцов, проверке выполнения условий для всех элементов матрицы и проверке выполнения условий хотя бы для одного элемента матрицы. Полезно также использование условного форматирования ячеек в Excel. Например, выделение цветом отрицательных и положительных значений производных в таблице позволяет акцентировать внимание на достаточном условии существования экстремума.

3. Выполнять действия по импорту и экспорту данных из одного ресурса в другой.

При выполнении импорта/экспорта данных сле- дует обратить внимание на несогласованность некоторых форматов в различных программах. Студентов следует познакомить с переносом данных из EXCEL в R и обратно с использованием буфера обмена и с помощью задания пути обращения. Отладка подобных команд способствует более прочному формированию необходимых навыков. Кроме этого полезно научить студентов обращаться к пользовательской функции, сохраненной в другом файле.

4. Визуализировать данные в средах Excel u R.

Основам визуализации данных студенты учатся в процессе построения графика функции, нескольких графиков в одной системе координат; форматирования области построения (оси, маркеры, подписи). Отрабатываются навыки составления таблицы значений для диаграммы через задание номера и шага, подбор масштаба для наиболее удачного построения эскиза графика и выбор окрестности для изображения особых точек графика. Визуализация используется для демонстрации апроксимации функции с помощью формулы Маклорена, анализа поведения функции по совместным графикам функции и второй производной, сравнения графиков точного и приближенных решений дифференциального уравнения, построения поверхностей и линий уровня функций двух переменных.

5. Использовать встроенные математические, финансовые, экономические функции.

При работе в Excel полезно познакомить студентов с возможностями использования встроенных функций для процентных вычислений: БС, ПС, ставка, Кпер, Плт, БС, БЗРАСПИС, ОСПЛТ, ПРПЛТ, ОБЩДОХОД, ОБЩПЛАТ. Темы по расчету депозитов и кредитных схем выходят за рамки дисциплины «Математика», но, как правило, с интересом воспринимаются студентами и стимулируют их мотивацию.

6. Знать основные методы и особенности использования приближенных вычислений для решения уравнений, дифференцирования и интегрирования функций.

В рамках дисциплины есть возможность разобрать и продемонстрировать приближенные методы вычислений: оценка значений производной по двухточечной формуле, приближенное вычисление функции через разложение по формуле Маклорена, решение уравнений и уточнение экстремумов с помощью изменения окрестности и метода касательных, с помощью подбора параметра в EXCEI и команд which.min $(\operatorname{abs}(f(x-y 0)))$, uniroot, uniroot.all, which.max $(f(x))$ и which.min $(f(x))$, optimize в R, решение дифференциальных уравнений по схеме Эйлера. Особый акцент при выполнении приближенных вычислений следует делать 
на использовании точности: заданной заранее, возможной или наиболее целесообразной.

В заключении приведем несколько примеров возможностей формирования первичных навыков использования инструментов EXCEI и R для визуализации данных и вычислительной работы на семинарских занятиях.

Пример 1. На первом занятии первого семестра по теме «Введение в Excel» обсуждаются вопросы:

- типы данных;

- форматирование электронных таблиц;

- комбинации клавиш.

В конце занятия предлагается составить в Excel таблицу курса доллара ЦБ РФ за август 2019, в которой в первом столбце стояла бы дата, во втором столбце курс доллара, в третьем - процент относительного изменения курса (все столбцы подписаны сверху). Данные взять с сайта http://www.val.ru. Как видим, с первых занятий формируются навыки оперативно находить необходимую информацию на российских ресурсах и оформлять ее в виде таблиц.

Пример 2. Во втором семестре на занятиях по темам «Задание векторов и матриц в R (RStudio)» и «Сохранение результатов в R и импорт/экспорт данных из Excel (RStudio)»:

- приводится решение заданий по импорту/экспорту данных из EXCEL в R и обратно;

- особенности трансформации форматирования числовых данных;
- обращение к элементам массива в R.

После демонстрации примеров можно предложить студентам для самостоятельного решения задание:

Скачать из интернета и сохранить в файле money. xlsx данные за последний полный месяц о курсе USD и EUR и записать их в файл money.rds не используя буфер обмена. Проверить результат, считав обратно данные из money.rds и отправив их в какой-нибудь новый xlsx-файл.

В ряде случаев может потребоваться произвести автозамену точки на запятую в Excel, если данные о курсах валют содержат десятичным разделителем точку.

Умение находить и помещать данные в таблицу студенты решают на новом уровне. Можно предлагать студентам брать данные с англоязычных сайтов.

В результате изучения дисциплины «Компьютерный практикум» у студентов формируются важные цифровые навыки, необходимые для современного специалиста экономического и финансового профиля. Они получают развитие и доводятся до некоторого автоматизма в рамках дисциплины «Анализ данных» на втором курсе. Цифровые навыки и умения трансформируются в цифровые компетенции, которые в дальнейшем закрепляются, расширяются при изучении прикладных дисциплин на старших курсах: «Финансовая математика», «Построение и оценка моделей машинного обучения», «Методы визуализации данных», «Интеллектуальные технологии в управлении рисками», «Базы данных».

\section{ЛИТЕРАТУРА}

1. Национальная программа «Цифровая экономика Российской Федерации». URL: http://government.ru/rugovclassifier/614/events/

2. Вызовы цифровой экономики: итоги и новые тренды: сборник статей II Всероссийской научно-практической конференции (г. Брянск, 07 июня 2019 г.) [Электронный ресурс]. - Брянск: Брян. гос. инженерно-технол. ун-т., 2019. - 696 c. URL: http://bgitu.ru/upload/iblock/76b/Sbornik_Vyzovy_tsifrovoy_ ekonomiki_2019.pdf

3. Экономические, финансовые и управленческие аспекты внедрения цифровых технологий: сборник статей и тезисов докладов XXIII международной научно-практической конференции (15,16 мая 2019 г.) Уральский филиал Финуниверситета. - Москва. Издательство «Перо», 2019. —240 c. [Электронное издание] URL: http://www.fa.ru/fil/chelyabinsk/science/Documents/conferences_monographies_2019_02.pdf

4. Цифровые технологии в социально-экономическом развитии России: взгляд молодых: сборник статей и тезисов докладов XVI национальной научнопрактической конференции студентов, магистрантов и аспирантов с международным участием (18 февраля 2020 г.) / Уральский филиал Финуниверситета. - Москва: Издательство «Перо», 2020. [Электронное издание] URL: http://www.fa.ru/fil/chelyabinsk/science/Documents/SBORNIK2020\%281\%29.pdf

5. Беляева Г.Д., Макарец А.Б., Федоренко Г.А. Подготовка кадров для инновационной экономики в условиях модернизации системы высшего образования / Беляева Г.Д., Макарец А.Б., Федоренко Г.А. // Современные проблемы науки и образования, 2018. - №6. - С.45-48.

6. Матвеева Е.П., Кощеева Е.С. К вопросу о подготовке бакалавров к цифровизации образования. Педагогическое образование в России, 2019. - № 7. - С. $22-29$.

7. Платонова Т. Е. Проблемы внедрения технологий цифровой экономики на современном этапе развития экономического образования в россии. Вестник Алтайской академии экономики и права, 2019. - № 5 (часть 1) - С. 116-120

8. Коннова Л.П., Липагина Л.В., Рылов А.А., Степанян И.К. Ранняя профилизация в обучении математике будущих экономистов и менеджеров: Научная монография / Л.П. Коннова, Л.В. Липагина, А.А. Рылов, И.К. Степанян. - М.: Прометей, 2019. - 232 с.

9. Зададаев С.А. «Компьютерный практикум». Рабочая программа дисциплины для студентов, обучающихся по направлению подготовки 38.03 .01 
«Экономика», все профили очной формы обучения. - М.: Финансовый университет, Департамент анализа данных, принятия решений и финансовых технологий, $2017-33$ с.

10. Анализ данных. Рабочая программа дисциплины для студентов, обучающихся по направлению подготовки 38.03 .01 «Экономика» (программа подготовки бакалавра). - М.: Финансовый университет, департамент анализа данных, принятия решений и финансовых технологий, 2017. - 23 с.

(c) Коннова Лариса Петровна, Степанян Ирина Кимовна (fpk0701@mail.ru).

Журнал «Современная наука: актуальные проблемы теории и практики»

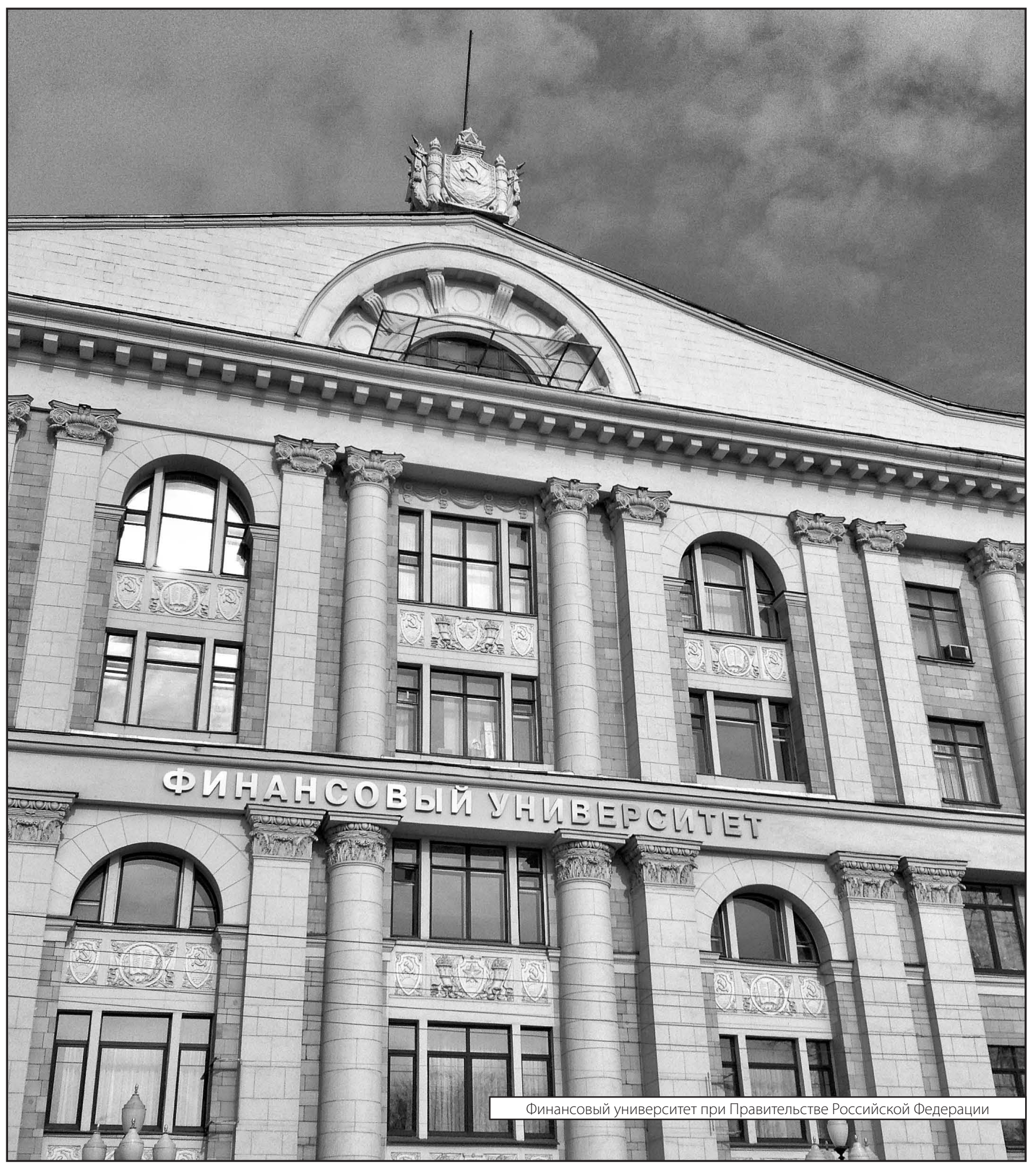

